\title{
Chemical Characterization of Exhaust Gases from Compression Ignition Engine Fuelled with Various Biofuels
}

\author{
Małgorzata Odziemkowska ${ }^{1 *}$, Joanna Czarnocka ${ }^{1}$, Andrzej Frankiewicz ${ }^{1}$, \\ Małgorzata Szewczyńska², Anna Lankoff ${ }^{3}$, Joanna Gromadzka-Ostrowska ${ }^{4}$, \\ Remigiusz Mruk ${ }^{4}$
}

${ }^{1}$ Automotive Industry Institute, 55 Jagiellońska Str., 03-301 Warsaw, Poland

${ }^{2}$ Central Institute for Labour Protection - National Research Institute, 16 Czerniakowska Str., 00-701 Warsaw, Poland

${ }^{3}$ Jan Kochanowski University, 15 Świętokrzyska Str., 25-410 Kielce, Poland

${ }^{4}$ Warsaw University of Life Sciences, 166 Nowoursynowska Str., 02-787 Warsaw, Poland

Received: 9 August 2016

Accepted: 20 December 2016

\begin{abstract}
The authors have examined the influence of biocomponents of different origin on exhaust gases emitted from a light duty vehicle with a compression ignition engine. The car was fuelled with diesel fuel containing $20 \% \mathrm{~V} / \mathrm{V}$ fatty acid methyl esters and diesel fuel with $13 \% \mathrm{~V} / \mathrm{V}$ hydrotreated vegetable oils and $7 \% \mathrm{~V} / \mathrm{V}$ fatty acid methyl esters. Commercial diesel fuel containing $7 \% \mathrm{~V} / \mathrm{V}$ esters was a reference. The tests were performed on the chassis dynamometer in static engine operating conditions. It was stated that the addition of mentioned biocomponents into diesel fuel slightly changed the concentration of regulated components in exhaust gases with/without after-treatment devices. The presence of bio-components has reduced nitrogen oxide concentration in the treated exhaust gases as compared to the commercial diesel. We observed no trends of changes in unburned hydrocarbon concentrations depending on the type of tested fuels and presence of the diesel particle filter. Unburned hydrocarbons consisted mainly of fractions containing up to five carbon atoms per molecule. Whatever the type of fuel examined, carbonyl compounds such as formaldehyde and acetaldehyde were found only in the untreated exhaust gases.
\end{abstract}

Keywords: biofuels, tailpipe emissions, carbonyl compounds, compression ignition engine, aftertreatment devices

*e-mail: m.odziemkowska@pimot.eu 


\section{Introduction}

Transportation is a major source of atmospheric pollutants [1]. Some substances emitted from vehicle exhausts constitute environmental and health hazards. We could decrease pollutant emissions by using biofuels, which also offer greenhouse gas emission reductions by analysing them on a full lifecycle basis. Biofuels are produced from renewable feedstocks, therefore their use as an energy source for transportation can be considered a good way to reduce dependence on fossil fuels.

The use of biofuels containing biocomponents such as fatty acid methyl esters (FAME) or hydrotreated vegetable oils (HVO) has an effect on engine performance and exhaust gas emissions. Results on emissions for experiments with various biofuels referred to in literature differ with respect to engine design, test methods, and test conditions. A large number of studies were conducted in terms of carbon oxide (CO), nitrogen oxides ( $\mathrm{NOx}$ ), unburned hydrocarbons (HC), particle matters (PM), and carbon dioxide $\left(\mathrm{CO}_{2}\right)$ emissions - especially for fuels containing FAME, and the results are widely available in many scientific articles. However, determining the emissions of individual hydrocarbons and their derivatives (including carbonyl compounds (CC) (aldehydes and ketones) and polycyclic aromatic hydrocarbons (PAH) in exhaust gases from engines powered by biofuels) is also important, because part of the above-mentioned substances are toxic. Some hydrocarbons are reactive and they contribute to the formation of ground-level ozone [2]. Aldehydes also have a carcinogenic and ozone formation potential [3].

Labeckas and Slavinskas [4] evaluated the impact of different biofuels based on rapeseed oil on regulated exhaust emissions and smoke opacity of direct injection compression ignition engines operating at different loads and speeds. Qi et al. [5] conducted similar studies for biofuels based on soybean oil. The research stated that the $\mathrm{CO}$ emissions were lower, but the NOx emissions were higher in comparison with diesel. Man et al. [6] reached a similar conclusion by examining biodiesel from waste cooking oil, while Utlu and Kocak [7] demonstrated in their studies that frying oil methyl esters as alternative diesel fuel decreased both $\mathrm{CO}$ and NOx emissions. The tests performed by Karavalakis et al. [8] on the chassis dynamometer confirmed a tendency for lower $\mathrm{CO}$ and $\mathrm{HC}$ emissions for biofuels in reference to fossil fuel.

Examinations of the above-mentioned authors as well as Guarieiro et al. [9] and He et al. [10] showed that the use of biofuels with FAME caused the change of carbonyl compound emissions compared with diesel fuel. Formaldehyde, acetaldehyde, acrolein, and acetone were the most significant group of carbonyl compounds in exhaust gases both for biofuels and diesel. Man et al. [6] found a significant increase of carbonyl compound emissions with increasing biodiesel content in the fuel. Guarieiro et al. [9] presented other conclusions: except for acrolein and formaldehyde, all carbonyl compounds showed a clear trend of reduction in the emissions from B2 to B100.

The influence of FAME on emissions trends is difficult to conclude generally due to contradictory reports. This was confirmed by the overviews prepared by Fazal et al. [11] and Pullen and Saeed [12]. Fazal et al., based on scientific articles, assessed the possibility of using FAME to supply vehicles. In terms of emissions, they stated that using biodiesel can reduce $\mathrm{HC}, \mathrm{CO}$, and particulate matter (PM) emissions, but NOx emissions may increase. A few other studies have also reported on the decreasing NOx emissions. Pullen and Saeed found that the dominant emissions trends were usually an increase in oxides of nitrogen, and a decrease in carbon monoxide, particulate matters, unburned hydrocarbons, and aromatic compounds. The changes in emissions of carbonyl compounds are less certain. The results also showed that all the emissions were significantly involved with the engine load.

Kuronen et al. [13] utilized HVO and diesel fuel to supply heavy-duty diesel engines as well as buses. They achieved reduction in all regulated emission components. Kim et al. [14] carried the tests out in terms of performance and emission characteristics of light-duty engines powered by diesel fuel blended with HVO, iso-HVO, or FAME. Biofuels resulted in lower amounts of $\mathrm{HC}$ and $\mathrm{CO}$ in exhaust gases than diesel fuel. They observed that NOx emissions were dependent on engine loads. The amount of emitted NOx was larger at the higher engine load regardless of the type of biofuel and the biocomponent concentrations. The effects of HVO on the regulated and unregulated emissions of heavy-duty engines and a passenger car fleet were examined by Singer et al. [15]. The results showed that the use of HVO caused a reduction of all heavy-duty engine emissions compared with diesel. In comparison with biodiesel, HVO also reduced NOx emissions. These trends were not confirmed in the case of passenger cars.

No S.-Y. [16] reviewed studies on combustion and emission characteristics of compression ignition engines fuelled with neat HVO, blends of HVO with petrodiesel, and HVO with additives. He stated that the use of HVO enables appreciable reductions in $\mathrm{NOx}, \mathrm{PM}, \mathrm{HC}$, and $\mathrm{CO}$ emissions without any changes to engine parameters. Rantanen et al. [17] also investigated exhaust gas emissions for passenger cars fueled by HVO and diesel blends without changing engine parameters. They found that these blends decreased both regulated and unregulated exhaust gas emissions. Decreases in $\mathrm{CO}, \mathrm{HC}$, and PM emissions were dependent on the proportion of HVO. Reduced emissions in the case of NOx was not evident.

Millo et al. [18] analyzed the effects of blending of ultra-low-sulfur diesel with rapeseed methyl esters and hydrotreated vegetable oil on the performance and emissions of European passenger car diesel engines featuring advanced combustion technologies and closedloop combustion control. $\mathrm{HC}$ and $\mathrm{CO}$ emissions were significantly reduced for both tested fuels at low and medium loads. NOx emissions were comparable to those of diesel fuel. 
Table 1. Technical data of the test car.

\begin{tabular}{|c|c|}
\hline Test object & Fiat Panda (2014) \\
\hline Engine & $1.3 \mathrm{JTD}$ \\
\hline Engine capacity & $1,248 \mathrm{~cm}^{3}$ \\
\hline $\begin{array}{c}\text { Number of cylinders and } \\
\text { layout }\end{array}$ & 4 n-line \\
\hline Max. power & 75 bhp \\
\hline Max. torque & $190 \mathrm{Nm}$ \\
\hline Type of injection system & $\begin{array}{l}\text { Direct, common rail } 3 \mathrm{RD} \\
\text { generation }\end{array}$ \\
\hline Intake system & Turbocharged \\
\hline Transmission & 6-speed gearbox \\
\hline Emission stage & Euro 5 \\
\hline
\end{tabular}

Despite the large number of comparative studies regarding regulated emissions of engines fuelled with FAME or HVO as neat fuel and as well as blends with diesel, there is a gap of studies on the composition of the exhaust gases from light-duty vehicles operating on diesel fuel blended with FAME and HVO. Therefore, the main goal of this study was the detailed chemical characterization of exhaust gases resulting from the combustion of various biofuels ( $1^{\text {st }}$ and $2^{\text {nd }}$ generations) in a car's engine. Both raw exhaust gases leaving the engine and exhaust gases purified by the catalytic converter and DPF were analysed. These tests were conducted to separate the effect of a kind of burned fuel from the influence of the treatment system on the emitted exhaust gases composition. We examined the influence of biofuels containing FAME and HVO on regulated and unregulated exhaust emissions.

The presented results concern exhaust gases emitted from a light-duty car fulfilling the requirements of Euro 5. The tests were performed on the chassis dynamometer in static engine operating conditions (constant vehicle and engine speed). Two exhaust systems were tested: with catalytic reactor and diesel particle filter (DPF) and without these devices.

We analysed the exhaust gases resulting from the combustion of two biofuels. The first was diesel with $20 \%$ FAME, the second was diesel fuel with $7 \%$ FAME and $13 \%$ HVO. The commercial diesel fuel (containing 7\% esters) was used as the reference fuel. The concentration of regulated substances such as $\mathrm{CO}, \mathrm{NOx}, \mathrm{HC}$, and $\mathrm{PM}$ were examined. In addition, the contents of hydrocarbons depending on carbon number in the molecule were specified. The quantitative analysis of carbonyl compounds was carried out. Measurements of $\mathrm{CO}_{2}$ concentrations were also provided. The results of PM emissions and polycyclic aromatic hydrocarbons adsorbed on PM are presented in [19].

Exhaust gases produced from the combustion of diesel fuel and various biofuels (with and without DPF) were used for in vivo studies, but this article does not include those results.

\section{Materials and Methods}

Vehicle and Fuels

We used a Fiat Panda passenger car with a 1.3 JTD engine in the tests. It had a common rail third-generation injection system. The exhaust system of the vehicle was equipped with a catalytic reactor and a diesel particle filter (DPF). The vehicle fully met all Euro 5 standard requirements. The basic car specifications are given in Table 1.

The Fiat Panda was fuelled by the three following fuels:

- Commercial diesel fuel containing 7\% FAME compliant with European diesel criteria (EN 590 standard) [20], hereafter referred to as DF.

- A blend of commercial diesel fuel with 13\% FAME, hereafter referred to DF+FAME.

Table 2. Properties of tested fuels.

\begin{tabular}{|c|c|c|c|c|c|}
\hline Property & Unit & DF & DF+FAME & DF+HVO & Test method \\
\hline Cetane number & -- & 52.5 & 53.6 & 53.1 & EN ISO 5165 \\
\hline Density at $15^{\circ} \mathrm{C}$ & $\mathrm{kg} / \mathrm{m}^{3}$ & 839.5 & 843.3 & 829.9 & EN ISO 12185 \\
\hline Policyclic aromatic hydrocarbons & $\%(\mathrm{~m} / \mathrm{m})$ & 1.3 & 1.4 & 1.3 & EN 12916 \\
\hline Sulfur content & $\mathrm{mg} / \mathrm{kg}$ & 5.7 & 4.6 & 4.8 & EN ISO 20846 \\
\hline Oxidation stability & $\mathrm{h}$ & 40.6 & --- & 47.2 & EN 15751 \\
\hline Lubricity, WS 1,4, at $60^{\circ} \mathrm{C}$ & $\mu \mathrm{m}$ & 218 & 199 & 197 & EN ISO 12156-1 \\
\hline Viscosity at $40^{\circ} \mathrm{C}$ & $\mathrm{mm} / \mathrm{s}$ & 3.002 & 3.088 & 2.983 & EN ISO 3104 \\
\hline Distillation: $95 \%(\mathrm{~V} / \mathrm{V})$ recovered at & ${ }^{\circ} \mathrm{C}$ & 357.1 & 355.3 & 353.9 & EN ISO 3405 \\
\hline Cold filter plugging point & ${ }^{\circ} \mathrm{C}$ & -30 & -7 & -30 & EN 116 \\
\hline Cloud point & ${ }^{\circ} \mathrm{C}$ & -9 & -5 & -10 & ISO 3015 \\
\hline
\end{tabular}


- A blend of commercial diesel fuel with $13 \%$ HVO, hereafter referred to DF+HVO.

Pure FAME met the European standard requirements (EN 14214) [21]. The properties of HVO were checked in accordance with the requirements of EN 590 standard. The main properties of diesel fuel and biofuels are listed in Table 2.

Diesel fuel was used as a reference fuel. All the tested fuels met the EN 590 standard requirements.

\section{Experimental Setup}

The experiments were performed on a Schenck Komeg EMDY 48 chassis dynamometer at the Automotive Industry Institute's Engine and Chassis Laboratory in static working conditions of the engine. The engine speed was $1,350 \mathrm{rpm}$. The tests was conducted at $45 \%$ load with a vehicle speed of $43.75 \mathrm{~km} / \mathrm{h}$ and a 50 load with a vehicle speed of $20.00 \mathrm{~km} / \mathrm{h}$. These conditions were established to achieve high exhaust gas temperature, which prevented excessive clogging of the DPF. Temperature of the coolant system was $94^{\circ} \mathrm{C}$.

Two exhaust gas systems were tested: with and without after-treatment devices. The investigations without converter and filter involved modification of the Panda's exhaust gas system. That modification consisted of removing the particulate filter and the catalytic reactor and replacing them with pipe sections with respective connections of pressure and exhaust gas temperature sensors. Additionally, the software of electronic unit control of the engine was changed, and sequences responsible for the control of particulate filter were removed.

The harmful substance concentrations in exhaust gases of the car fuelled by two biofuels were measured and the results were compared with pollutant concentrations in gases generated from DF combustion. The analysis covered regulated and unregulated components of exhaust gases. The terms "regulated" and "unregulated" indicate whether the component is subject to legislative limits.

The measurements of exhaust gases were conducted after stabilizing the working conditions of the test car.

\section{Methods of Sampling and Quantitative Analysis of Exhaust Gases}

For the determination of the regulated emissions components we used a constant volume sampler (CVS) [22] and a system of integrated MEXA-7200D analyzers from HORIBA. The nitric oxides were determined using a chemiluminescence detector. HC was measured by a $g$ as analyzer equipped with flame ionization detector (FID) and $\mathrm{CO}$ with a non-dispersive infrared analyzer.

The tailpipe gases were sampled for individual unburned C1-C12 hydrocarbon analysis using fluoropolymer film bags with polypropylene fitting septa/tube. Exhaust fumes were sucked through the pump at a rate of about $6 \mathrm{~L} / \mathrm{min}$. The volume of each bag was approximately $20 \mathrm{~L}$. The sampling set-up also included filters to remove the particulate matters and moisture. To maximize sample integrity, sample bags were hermetic and were not exposed to bright light.

For the purpose of collecting carbonyl compounds, the exhaust gases were passed through an acidified 2,4-dinitrophenylhydrazine (DNPH) coated silica bed at a rate of about $20 \mathrm{~L} / \mathrm{h}$. Aldehydes and ketones present in gases were trapped by reacting them with DNPH to stabilize a form of hydrazone derivative with a strong ultraviolet absorption spectrum. The exhaust gases were also passed through a glass microfiber filter to remove particulates. The duration of a single sampling was established at $10 \mathrm{~min}$. The cartridges $(6 \mathrm{~mm}$ outer diameter x $110 \mathrm{~mm}$ length) were packed with two adsorbent beds: $300 \mathrm{mg}$ and $150 \mathrm{mg}$. The second bed was a backup section to determine if a breakthrough of exhaust gas contaminants occurred on the front portion.

The analytical methods used for the analysis of the group of hydrocarbons and carbonyl compounds were based on those approved by the U.S. Environmental Protection Agency [23].

We used gas chromatography (GC) to determine hydrocarbon concentrations according to the number of carbon atoms in a molecule. The separation of hydrocarbon fractions was performed on a nonpolar capillary column. The gaseous samples from bags were transferred into the gas chromatograph by means of the gas sampling valves with a gas sample loop. A flame ionization detector was used to quantitatively determine unburned hydrocarbons. A calibration was performed with a gas mixture of n-alkanes in nitrogen. The contents of the particular fractions were calculated as the sum of the peak areas between each n-alkanes based on the n-alkane with flame ionization detector.

We determined the carbonyl compounds collected in the cartridges with DNPH using high-performance liquid chromatography with diode array detection (HPLC-DAD). The compounds were detected at $365 \mathrm{~nm}$. Before HPLC analysis the carbonyl derivatives were extracted from cartridges with acetonitrile. A detailed description about sample preparation and conditions of chromatographic analysis can be found in [24].

\section{Results and Discussion}

\section{Regulated Components}

The results of harmful substance concentrations in diluted exhaust gases without after treatment for two biofuels in comparison with commercial diesel fuel are summarised in Fig. 1. Additionally, $\mathrm{CO}_{2}$ concentrations are presented. There are no set specific requirements regarding emissions of $\mathrm{CO}_{2}$. Vehicle $\mathrm{CO}_{2}$ emissions are impacted by fuel consumption.

The data showed in Fig. 1a) point out that the highest $\mathrm{CO}$ concentration in exhaust gases was measured for DF+FAME biofuel. For the load of $50 \%$, the increase of this parameter was $16 \%$ (in relation to $\mathrm{DF}$ ). CO 
a) 口DF 口DF+FAME aDF+HVO

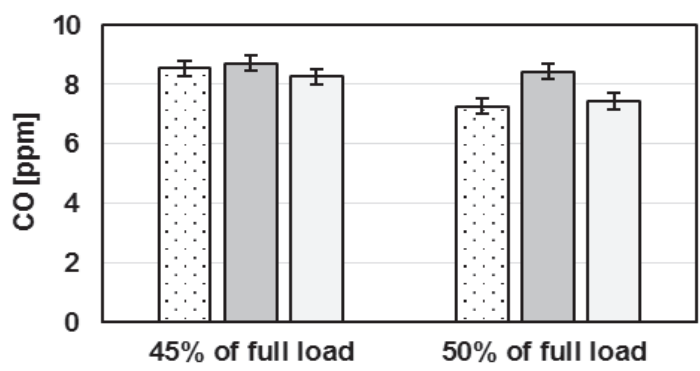

b)

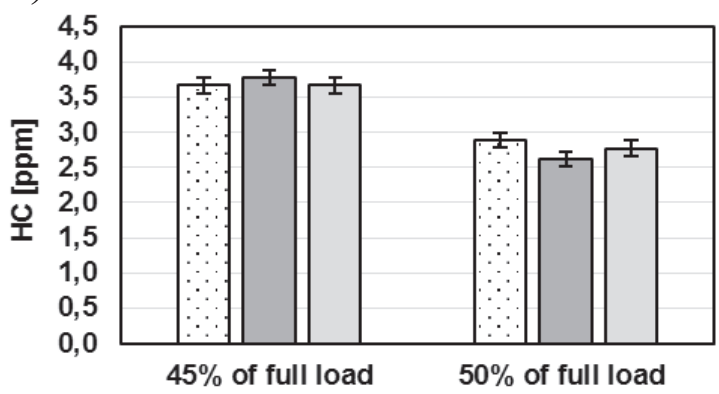

c)

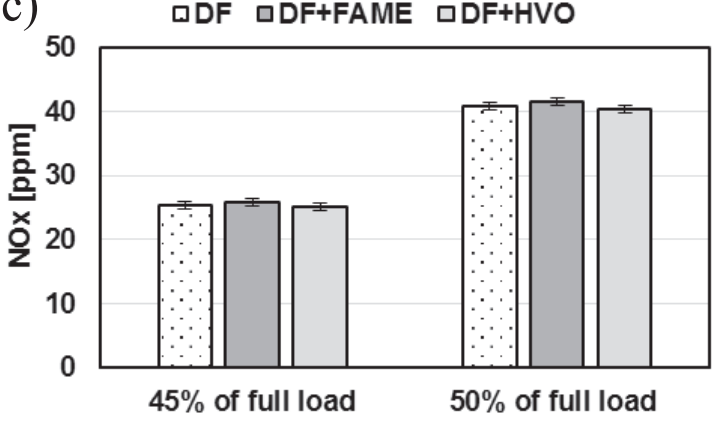

d)

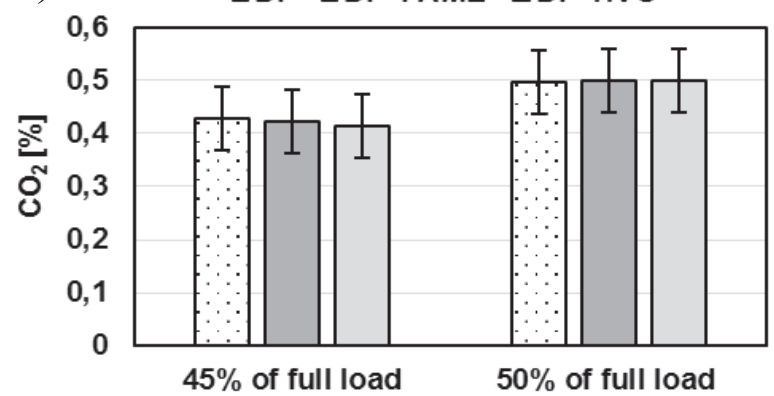

Fig. 1. The concentrations of harmful substances in exhaust gases without after treatment at different engine loads and engine speed of 1,350 rpm: a) - carbon monoxide, b) - hydrocarbons, c) - nitrogen oxides, d) - carbon dioxide.

concentration changes in exhaust gases for $\mathrm{DF}+\mathrm{HVO}$ were lower $(-3.3 \%$ and $2.3 \%$ for the loads $45 \%$ and $50 \%$, respectively) compared with DF+FAME. There were no significant differences of $\mathrm{HC}$ concentrations for the load of $45 \%$, regardless of the supplying fuel type. However, for the load of $50 \%$ there was a significant decrease of $\mathrm{HC}$ concentration for biofuel with FAME: $9.3 \%$. In the case of biofuel with HVO reduction, a)

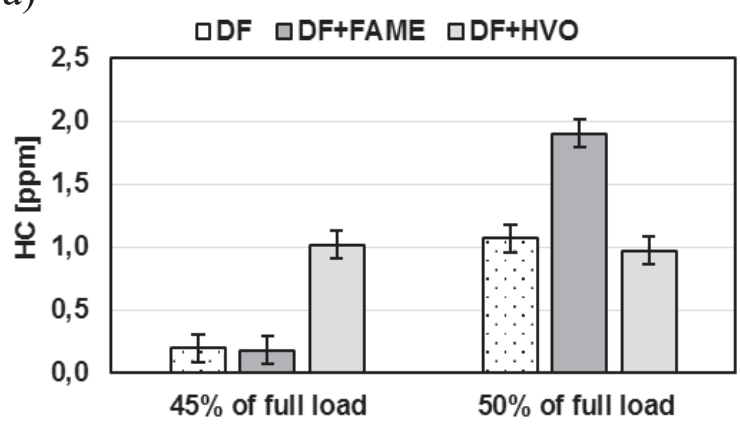

b)

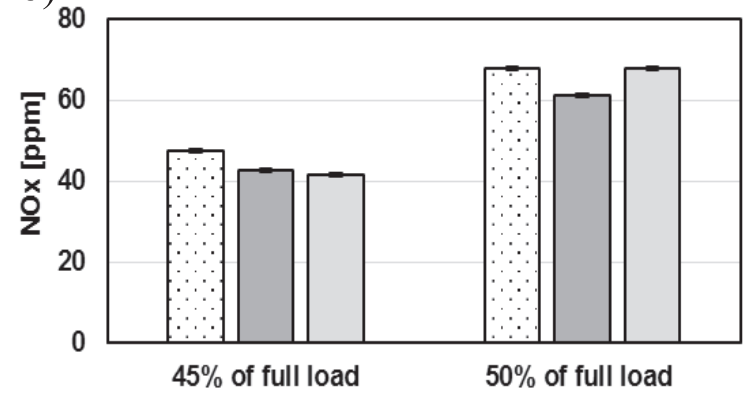

Fig. 2. Concentrations of harmful substances in exhaust gases with after treatment at different engine loads and engine speed of 1,350 rpm: a) - hydrocarbons, b) - nitrogen oxides.

this parameter amounted to $4.2 \%$. NOx concentration changes in exhaust gases depending on the fuel type, for applied loads, were in the range $-1.4-2.1 \%$. In conducted tests, the lowest NOx concentration was obtained for the DF+HVO biofuel. Likewise, there was a lack of significant difference of $\mathrm{CO}_{2}$ concentrations for the given load.

Taking into account the results of emissions measurements on chassis dynamometer for exhaust gases without treatment, the differences between regulated emissions for biofuels containing FAME or HVO at given engine load are not significant. This is probably due to inconsiderable differences of tested fuel quality parameters. The slight differences of emissions for diesel and DF+HVO also resulted from the chemical character of HVO, which consists of hydrocarbons like diesel fuel. The higher $\mathrm{CO}$ concentration in the case of DF+FAME, characterized by the highest FAME content of the compared fuels, may be related to physicochemical properties of esters, including their higher viscosity $\left(4,306 \mathrm{~mm}^{2} / \mathrm{s}\right.$ at $40^{\circ} \mathrm{C}$ for FAME compared to $3,002 \mathrm{~mm}^{2} / \mathrm{s}$ at $40^{\circ} \mathrm{C}$ for $\mathrm{DF}$ ). This parameter has an influence on a proper fuel spray in the combustion chamber and, consequently, on the combustion process. The preferred $\mathrm{HC}$ concentration reduction for biofuels at a $50 \%$ load may be due to the higher cetane number of biofuels compared to diesel.

The presented data did not confirm the results obtained by other researchers $[4,8,13]$, who noted the positive impact of biocomponents on $\mathrm{CO}$ and $\mathrm{HC}$ emissions compared to diesel. 
In the presented studies, NOx concentration increased at higher engine loads, regardless of the type of fuel and biocomponents, which is consistent with the conclusions of the authors of the study [14]. These results confirm the conclusion in the review [12] that the emissions were significantly involved with the engine load. As in [13, 17], it was found that $\mathrm{HVO}$ addition preferably reduces $\mathrm{NOx}$ concentration in exhaust gases.

The test results for exhaust gases with after treatment generated from the combustion of different fuels are shown in Fig. 2.

The values of $\mathrm{CO}$ concentrations were below a limit of quantification for all experiments, excluding one test at $45 \%$ of full load for biofuel containing HVO (the measured concentration of $\mathrm{CO}$ was $0.07 \mathrm{ppm}$ ). With a load of $45 \%$, HC concentration in exhaust gases for the $\mathrm{DF}+\mathrm{HVO}$ biofuel was significantly higher in comparison with the other two fuels. HC concentration of considered biofuel at $50 \%$ load remained at the same level. However, at the load of $50 \%$, for DF+FAME biofuel we found a very large change of $\mathrm{HC}$ concentration $(77.6 \%)$ in relation to the reference fuel. The biocomponent addition into diesel fuel had a beneficial influence on NOx concentration; the concentration of these compounds in exhaust gases from the engine fuelled by tested biofuels was lower than in exhaust gases from the engine powered by diesel fuel. $\mathrm{CO}_{2}$ concentration changes were negligible (from $-3.1 \%$ to $1.9 \%$ ) and depended on the engine load. For the lower load, $\mathrm{CO}_{2}$ concentrations for biofuels were slightly lower than for diesel fuel. For the higher load the trend was inversed.

Similarly, as in the case of untreated exhaust gases, the effect of biocomponents on emissions from the tailpipe with DPF was small at given engine load. The biggest differences in the concentrations were noted for unburned hydrocarbons, but these differences did not have a steady trend. This occurrence may be due to the fact that during the tests the operating parameters of the engine were unchanged, regardless of fuel type.

The results of the treated exhaust gas research in the field of hydrocarbon emissions confirm the conclusions in [6] that the trend of this parameter change depending on the biocomponent content cannot be determined. However, NOx reduction for fuels with biocomponents, as reported in the research, is consistent with the results presented in $[7,15]$.

The data indicate that regardless of the supplying fuel at the given engine load, purified exhaust gases are characterised by lower content of $\mathrm{CO}$ and $\mathrm{HC}$ than gases without purification, while the NOx concentrations in treated fumes are higher than in raw gases. The test results are consistent with the data reported in the literature. Some researchers have concluded that NOx varies according to the engine type and operating conditions, e.g. NOx relatively decreases at low loads and increases at high loads [14]. NOx concentration increase in treated exhaust gases can be connected with accepted tests conditions and with catalytic converter performance (dependent on exhaust gas temperature).
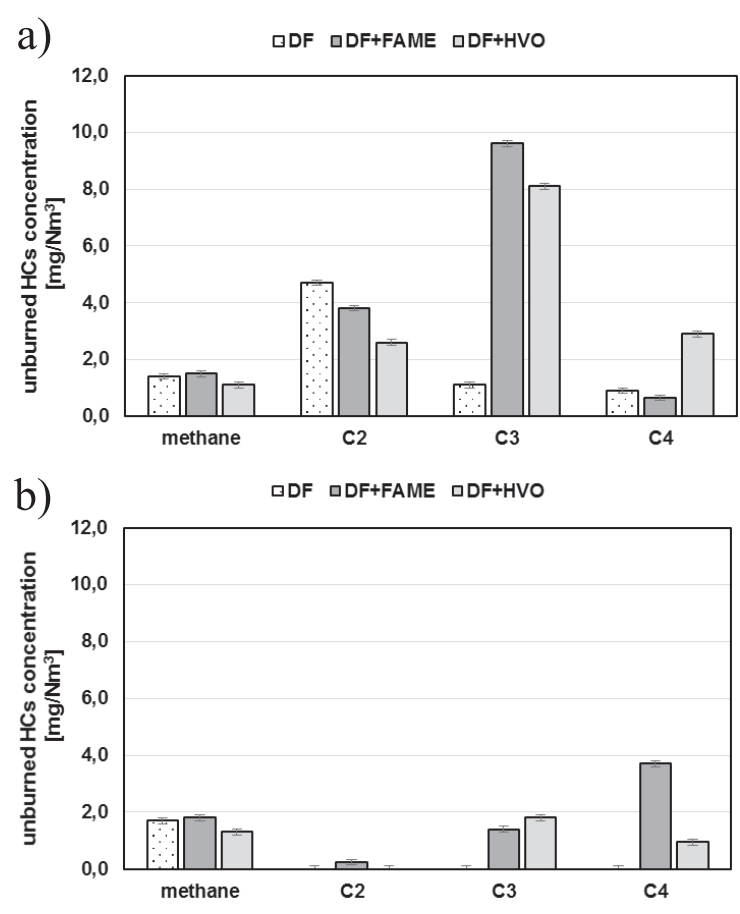

Fig. 3. Concentrations of individual hydrocarbons in exhaust gases generated at $45 \%$ of full load and engine speed of 1,350 rpm: a) - without aftertreatment, b) - with aftertreatment.

\section{Unregulated Components}

Most of the analyses of unregulated emissions are complicated (GC, HPLC, DNPH sampling), meaning that the margins of errors might be quite high. Therefore, presented results should be considered indicative only. The analysis below was performed for undiluted gases at $45 \%$ of engine load.

In diesel engines, the exhaust contains hydrocarbons derived from partly burned fuel. During the combustion process, some new types of hydrocarbons or components like aldehydes and ketones cab also be formed [2]. The main goal of hydrocarbons speciation was to determine the concentration of methane $\left(\mathrm{CH}_{4}\right)$, which as well as $\mathrm{CO}_{2}$ is a greenhouse gas. Quantitative analysis of the unburned components, shown in Fig. 3, indicates that hydrocarbons consist mainly of light fractions $\mathrm{C} 1-\mathrm{C} 4$, especially $\mathrm{C} 2$ and $\mathrm{C} 3$. The concentration of unburned hydrocarbons in treated exhaust gases is lower than in the raw exhaust gases. In case of diesel fuel, in treated exhaust gases, hydrocarbon concentrations decreased below the limit of quantification. $\mathrm{CH}_{4}$ concentration ranged from 1.1 to $1.8 \mathrm{mg} / \mathrm{Nm}^{3}$. Minor changes in methane concentration for the system with/without DPF are the result of the fact that methane is resistant to oxidation.

In the literature, there is a lack of data on the detailed analysis of the profile of unburned hydrocarbons in exhaust gases. Caplain et al. [1] provided the analysis that diesel engine exhaust gases consist mostly of aromatic hydrocarbons (75-93\%), straight or branched 


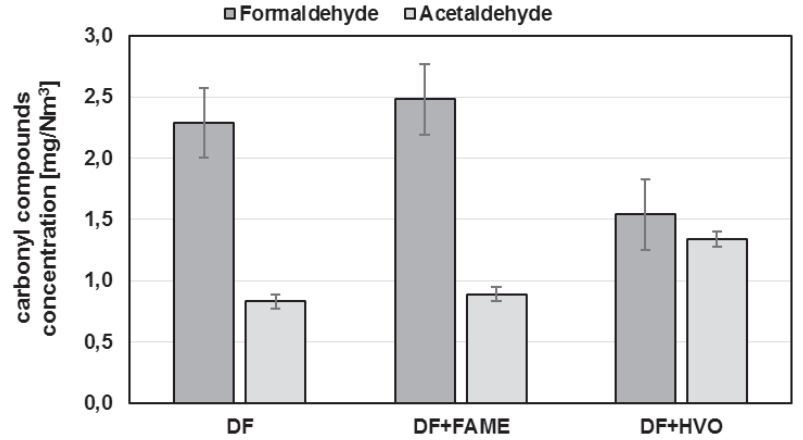

Fig. 4. The concentrations of carbonyl compounds in exhaust gases without after treatment generated from engine at $45 \%$ of full load and engine speed of 1,350 rpm.

chain alkanes (6-18\%), and carbonyl compounds $(0.1-2 \%)$. Siegl et al. [25] found that methane was 33\% of total hydrocarbon emissions from an engine fuelled with diesel fuel. From non-methane hydrocarbons there were the most light fractions: C2-C12. There is no data in the literature regarding the profiles of unburned hydrocarbons for biofuels. The results presented in Fig. 3 did not allow us to find a specific trend in the distribution of n-alkanes in exhaust gaseous samples depending on a kind of tested fuel.

Any aldehydes and ketones (carbonyl compounds) appearing in exhaust gases are formed from the engine and exhaust system [3]. The incomplete combustion of any hydrocarbons generates carbonyl compounds. Formaldehyde is the most abundant compound of carbonyl for both biofuels and diesel [10]. This work analyses concentrations of these compounds in tailpipe gases. Results are shown in Fig. 4. In the case of an exhaust system without DPF, aldehydes such as formaldehyde and acetaldehyde were determined quantitatively. Other aldehydes and ketones were not detected. For an exhaust system with DPF, concentrations of carbonyl compounds dropped below the detection limit.

The gaseous phase from the DF+FAME combustion contained more formaldehyde than from the DF combustion. Therefore, the increase of FAME content from 7 to $20 \%$ resulted in a slight increase in formaldehyde emission. $\mathrm{DF}+\mathrm{HVO}$ had a positive effect on formaldehyde concentration compared with commercial fuel, which may be the result of dilution of the FAME contained in DF. The highest level of acetaldehyde was measured in the case of $\mathrm{DF}+\mathrm{HVO}$ combustion. Acetaldehyde concentrations for DF and DF+FAME were similar.

Taking into account the obtained results of carbonyl compound emissions, it can be stated that they are consistent with the findings of other authors [8-10]: formaldehyde and acetaldehyde were the most abundant carbonyl compounds in exhaust gases for all tested fuels. The influence of biocomponent content is not so clear, e.g., in the study [13] is stated that HVO addition decreases unregulated emissions. In contrast, the results showed in [8] prove that the FAME application, irrespective of the raw material, has a negative influence on carbonyl compound emissions. This is not entirely confirmed by the results presented in this article. In [3] FAME negative effect on the on the emissions of certain carbonyl compounds was proven.

In consideration of conflicting results on the effect of biobased components on carbonyl compound emissions, further research in this area is needed.

\section{Conclusions}

Concentrations of harmful substances in exhaust gases emitted by cars fuelled with various biofuels containing FAME and HVO were analysed in comparison with diesel fuel. The studies covered regulated and unregulated components of exhaust gases. Two exhaust gas systems were tested: with and without after-treatment devices. The car engine was not subjected to any modification.

The experiments were performed on the chassis dynamometer in static working conditions of the engine. The Fiat Panda car equipped with a 1.3 JTD compression ignition engine met the requirements of the Euro 5 stage.

The following conclusions were drawn from this study:

- The addition of biocomponents such as FAME and $\mathrm{HVO}$ to diesel fuel slightly changed $\mathrm{CO}$ and NOx concentrations in exhaust gases with/without aftertreatment devices.

- In the case of raw exhaust gases, the CO concentration was slightly elevated for biofuel with FAME; the values of $\mathrm{CO}$ concentrations of treated gases were very low for all tested fuels.

- The addition of biocomponents into diesel fuel advantageously reduced NOx concentrations of treated gases.

- In exhaust gases we observed no trends of changes in $\mathrm{HC}$ concentration depending on the kind of tested fuels in the presence of DPF.

- The concentrations of unburned hydrocarbon fraction $\mathrm{C} 2-\mathrm{C} 3$ in treated exhaust gases were lower than in raw exhaust gases due to oxidation resistance and lacking changes in methane concentrations.

- Carbonyl compounds such as formaldehyde and acetaldehyde were determined only in raw exhaust gases, the highest concentrations of formaldehyde in exhaust was stated in the case of biofuel with esters, and the highest concentrations of acetaldehyde were for biofuel containing HVO.

- Regardless of the supplying fuel at a given engine load, treated exhaust gases were characterised by lower content of $\mathrm{CO}$ and $\mathrm{HC}$ and higher NOx concentration than gases without purification.

- Regardless of the supplying fuel at the given engine load, we saw a lack of significant differences in $\mathrm{CO}_{2}$ concentrations. 


\section{Acknowledgements}

This study was financially supported by the National Centre for Research and Development of Poland and cofinanced by the Polish-Norwegian Research Cooperation Programme in the project "Green fuels and human health - toxicity of engine emissions from $1^{\text {st }}$ and $2^{\text {nd }}$ generation biodiesel fuels" Pol-Nor/201040/72/2013.

\section{References}

1. CAPLAIN I., CAZIER F., NOUALI H., MERCIER A., DECHAUX J.-C., NOLLET V., JOUMARD R., ANDRE J.-M., VIDON R. Emissions of unregulated pollutants from European gasoline and diesel passenger cars. Atmos. Environ., 40, 5954, 2006.

2. NYLUND N.-O., ERKKILÄ K., LAPPI M., IKONEN M. Transit bus emission study: comparison of emissions from diesel and natural gas buses. Research report PRO3/ P5150/04 on 15.10.2004 by VTT Processes. Available online: http:/www.documan.net/d/Heavy-Duty-Vehicle-ChassisDynamometer-Testing-for.pdf (accessed on 20.10.2016)

3. KUMAR S., NAYEK M., KUMAR A., TANDON A., MONDAL P., VIJAY P., BHANGALE U.D., TYAGI D. Aldehyde, Ketone and Methane Emissions from Motor Vehicle Exhaust: A Critical Review. American Chemical Science Journal, 1 (1), 1, 2011.

4. LABECKAS G., SLAVINSKAS S. The effect of diesel fuel blending with rapeseed oil and RME on engine performance and exhaust emissions. Journal of KONES Internal Combustion Engines, 12 (1-2), 187, 2005.

5. QI D.H., CHEN H., GENG L.M., BIAN Y. ZH. Experimental studies on the combustion characteristics and performance of a direct injection engine fueled with biodiesel/diesel blends. Energy Conver. Manage., 51, 2985, 2010.

6. MAN X.J., CHEUNG C.S., NING Z., WEI L., HUANG Z.H. Influence of engine load and speed on regulated and unregulated emissions of a diesel engine fueled with diesel fuel blended with waste cooking oil biodiesel. Fuel, 180, 41, 2016.

7. UTLU Z., KOÇAK M.S. The effect of biodiesel obtained from waste frying oil on direct injection diesel engine performance and exhaust emissions. Renew. Energy, 33, 1936, 2008.

8. KARAVALAKIS G., STOURNAS S., BAKEAS E. Light vehicle regulated and unregulated emissions from different biodiesels. Sci. Total Environ., 407, 3338, 2009.

9. GUARIEIRO L.L.N., DE PAULA PEREIRA P.A, TORRES E.A., DA ROCHA G.O., DE ANDRADE J.B. Carbonyl compounds emitted by a diesel engine fuelled with diesel and biodiesel-diesel blends: Sampling optimization and emissions profile. Atmos. Environ., 42, 8211, 2008.

10. HE C., GE Y., TAN J., YOU K., HAN X., WANG J., YOU Q., SHAH A.N. Comparison of carbonyl compounds emissions from diesel engine fueled with biodiesel and diesel. Atmos. Environ., 43, 3657, 2009.
11. FAZAL M.A., HASEEB A.S.M.A., MASJUKI H.H. Biodiesel feasibility study: An evaluation of material compatibility; performance; emission and engine durability. Renew. Sust. Energ. Rev., 15, 1314, 2011.

12. PULLEN J., SAEED K. Factors affecting biodiesel engine performance and exhaust emissions - Part I: Review. Energy, 72, 1, 2014.

13. KURONEN M., MIKKONEN S., AAKKO P., MURTONEN T. Hydrotreated Vegetable Oil as Fuel for Heavy Duty Diesel Engines. SAE Technical Paper 2007-01-4031, 2007.

14. KIM D., KIM S., OH S., NO S.-Y. Engine performance and characteristics of hydrotreated vegetable oil in light duty diesel engines. Fuel, 125, 36, 2014.

15. SINGER A., SCHRÖDER O., PABST C., MUNACK A., BÜNGER J., RUCK W., KRAHL J. Aging studies of biodiesel and HVO and their testing as neat fuel and blends for exhaust emissions in heavy-duty engines and passenger cars. Fuel, 153, 595, 2015.

16. NO S.-Y. Application of hydrotreated vegetable oil from triglyceride based biomass to CI engines - A review. Fuel, 115, 88, 2014.

17. RANTANEN L., LINNAILA R., AAKKO P., HARJU T. NExBTL - Biodiesel Fuel of the Second Generation. SAE Technical Paper 2005-01-3771, 2005.

18. MILLO F., DEBNATH B.K., VLACHOS T., CIARAVINO C., POSTRIOTI L., BUITONI G. Effects of different biofuels blends on performance and emissions of an automotive diesel engine. Fuel, 159, 614, 2015.

19. CZARNOCKA J., ODZIEMKOWSKA M. Characterization of the polycyclic aromatic hydrocarbons emitted from a compression ignition engine powered with biofuels of the 1st and 2nd generation. CHEMIK, 70, 419, 2016.

20. EN 590:2013 Automotive Fuels - Diesel - Requirements and test methods

21. EN 14214:2012+A1:2014 Liquid Petroleum Products Fatty acid methyl esters (FAME) for use in diesel engines and heating applications - Requirements and test methods

22. KUMAGAI T. Improving the accuracy of Fuel Consumption Measurement in CVS system. HORIBA Technical Reports 42, 2014.

Available online: www.horiba.com/uploads/media/ R42E_11_070_01.pdf (accessed on 20.10.2016)

23. US Environmental Protection Agency, EPA (Compendium Method TO-11A). Determination of Formaldehyde in Ambient Air Using Adsorbent cartridge followed by High Performance Liquid Chromatography (HPLC) EPA 625/R-96/010b, Office of Research and Development, Cincinnati, OH, 45268, 1999. Available online: http://www3. epa.gov/ttnamti1/files/ambient/airtox/to-11ar.pdf (accessed on 20.10.2016)

24. SZEWCZYŃSKA M., DOBRZYŃSKA E., POSNIAK M. Application of HPLC to determination of aldehydes, ketones and polycyclic aromatic hydrocarbons in air samples collected in uncontrolled combustion sources. Chem. Anal. (Warsaw), 54, 349, 2009.

25. SIEGL W.O., HAMMERLE R.H., HERRMANN H.M., WENCLAWIAK B.W., LUERS-JONGEN B. Organic emissions profile for a light-duty diesel vehicle. Atmospheric Environment, 33, 797, 1999. 